\title{
Being typical and being individual
}

\section{Bacon, Henry}

Routledge

2019

Bacon , H 2019 , Being typical and being individual . in J Riis \& A Taylor (eds) , Screening Characters : Theories of Character in Film, Television, and interactive Media . Routledge , New York and London , pp. 77-92 . https://doi.org/10.4324/9780429422508-5

http://hdl.handle.net/10138/327617

https://doi.org/10.4324/9780429422508-5

acceptedVersion

Downloaded from Helda, University of Helsinki institutional repository.

This is an electronic reprint of the original article.

This reprint may differ from the original in pagination and typographic detail.

Please cite the original version. 
Henry Bacon

\section{Being typical and being individual}

Part of the actor's craft is to create an individual character who is recognizable as a representation of a certain category of people as required by the plot and thematic aspirations of the filmmakers. To a varying degree this takes place in terms of what Robert Scholes and Robert Kellogg refer to as "the representation of generalized types of actuality." "This "generalized connection with the real world" allows for recognition on the part of the spectator. It is based on the same often blurred logic of classification that necessarily takes place in our social environment as we seek to make sense of other people but in some purposefully aestheticized form. This entails certain significant differences in the purposes of classification. Types in fiction stand for something more general than an individual, either to ensure narrative clarity, to make a point about human behavior or social relations or for expressive purposes - all these functions may well combine in a variety of ways. The degree of individuation may be first of all a question of a degree of narrative economy: whereas narratively central characters may be rounded by a range of character traits that have complex plot functions and which make them interesting and induce more refined spectatorial engagement, lesser characters may have purely functional roles, in which case there is no pressing need to develop them to any significant degree. ${ }^{2}$

Typification and individuation should not be thought of as polar opposites. All encounters with real people as well as fictional characters begin with rough classifications and, depending on circumstances, may or may not then proceed through recognition of more refined traits toward appreciation of individuality. The basis of making sense of fictional characters as types and individuals is based on the way we classify people in real life encounters on the one hand, understanding of narrative conventions on the other. Both are conducive to the interplay of typifying and individuating momentums. In order to deepen our understanding how this actually 
works out, we have to explore the ways various kinds of typification function, first in real life, then in fiction. The crucial question is what kind of classificatory schema is in operation, first in creating characters by the filmmakers, and then in the mental construction of them by the spectator. Placing people or characters into clearly defined classes as happens in what is referred to as classical categorization leads to simplistic stereotypification, whereas more flexible classification, captured in the theory of modern classification, explains how we can recognize general features defining classes and individuals as being a matter of degree and acknowledge that the boundaries of the categories that guide flexible social orientation are blurred.

\section{Classifying real and fictional people}

The way fictional characters are typified reflects the way we in everyday life may or may not feel inclined to get to know a person we encounter at more depth. As Ervin Goffman points out:

When an individual enters the presence of others, they commonly seek to acquire information about him or to bring onto play information about him already possessed... If unacquainted with the individual, observers can glean clues from his conduct and appearance which allow them to apply their previous experience with individuals roughly similar to the one before them or, more important, to apply untested stereotypes to him. ${ }^{3}$

Typificatory and individuating tendencies in our encounters tend to function in a dialectical fashion. Peter Berger and Thomas Luckmann discuss human relationship on a continuum from anonymity to the kind of interest and intimacy enabled by face-to-face situations. They suggest that "I apprehend the other by means of typificatory schemes even in the face-to-face situation, although these 
schemes are more 'vulnerable' to his interference than in 'remoter' forms of interaction. ... The reality of everyday life contains typificatory schemes in terms of which others are apprehended and 'dealt with' in face-to-face encounters."4 They further point out that "most of the time, my encounters with others in everyday life are typical in a double sense - I apprehend the other as a type and I interact with him in a situation that is itself typical." ${ }^{\circ}$

While a film does not offer the possibility for face-to-face interaction, it does launch analogous schemata which guide our mental construction of characters: we start from basic classification and then refine our understanding to the degree that following the narrative requires in terms of recognizable situations and contexts. These establish relevance structures which have a major role in controlling what kind of features capture our attention and guide our recognition of individuals as well as the ways in which we classify them. In fiction this process is likely to be more crystallized than in real life because of our awareness of the nature of the story we are following as well as of what we think are the thematic concerns the story exemplifies. More or less conscious classification of a film in terms of, say, genres, auteurs or ideological contexts is highly likely to guide our recognition of types and their narrative cum thematic functions within situation typical of the genre in question. Yet, even within any such schema, a character may appear more or less individuated. Both in real life and in fiction there may appear to be a continuum from the merely stereotypical to fully individuated, but more often the way we conceive of real persons as well as fictional characters is more dialectical: individuation itself can be seen as a process on increasing refinement of applying of categories as heuristic devices.

Typifications tend to have a narrative character: Even in real life, apart from situations in which recognition takes place in terms of culturally shared scripts and roles, people may be said to have a narrative identity: the way we conceive of real people - ourselves included - rests to a great extent on the narratives which tell us how they or we have turned out to be have certain qualities, what the motivations of their or our own actions are and how these emerge from their or our 
background and take shape in a given situation. One of the most important talents of an actor is the ability to discern the phenomenal symptoms of people belonging to a variety of social configurations and how they manifest their internal states, their concerns and aspirations in ways calibrated by their social background and personal history. Critical theory offers a useful conceptual tool for analyzing this process. The sociologist Pierre Bourdieu discusses what he calls habitus as a structure of socially constructed patterns of behavior and action tendencies. Although it is essentially a result of a social process it is not always recognized as such. It emerges from the needs within spheres of practical life and is a crucial factor determining both the self-image and the public image of social classes starting from embodied behavior, through notions about proper behavior to a shared sense of values. As such it is heavily class and group bound, an organic part of social relationships tightly bound to economic and symbolic power. Above all, it is a factor which enables an individual to behave in a certain self-expressive way. From this point of view, every individual act can be recognized as a symptom of belonging to a class or a group. ${ }^{6}$ The actors challenge, then, is to exemplify the habitus of his or her character in order to make its class affiliation recognizable in terms of plot and thematics. This may be a matter of realistic aesthetics, but may equally well take the form of caricaturization, if the intention of the filmmakers is to satirize social types and relationships. Creating socially relevant characters may also serve the purposed of making a statement about the human condition, possibly in some historical context or more abstractly, seeking to throw light on the symptomatic factors that shape our lives.

Daniel Auteuil offers a superb example of creating an impression of a certain habitus in Mikael Haneke's Hidden (2005). Georges is a cultured bourgeois man who tries to suppress an incident in his childhood which has led to his Algerian borne foster brother Majid to being sent away from their home. When Georges and Majid (Maurice Bénichou) meet after decades of separation, with Georges suspecting Majid of being responsible for the harassment of his family, both actors bring out with remarkable finesse the difference in social standing that separation has 
induced between them and how that connects with their internal state as they assess each other in view both of their past history and their present situation - neither of which is ever made perfectly clear. The encounter is a great acting opportunity, as there are neither obvious real life scrips nor narrative conventions available that would allow for easy interpretation of the scene in terms of the types that the habitus of the characters suggest. The spectator is forced to draw conclusions almost exclusively on the basis of the body-language of the character: how honest are they toward each other and themselves? In assessing this the spectator has to try to construct on the basis of the sparse cues the film offers a narrative that could explain the emotional dynamics of this scene. As the story proceeds far beyond standard conventions, the spectator has to first draw on, and then question and refine, his or her knowledge of social types in seeking to understand why these characters behave as they do. ${ }^{7}$ This is just one example of how fiction crystallizes real life experience into more or less manageable patterns of relationships and does this primarily through a balancing act between individuation and typification.

\section{Classical and cognitive classification}

How do we cope with the tremendous gamut of phenomena that we encounter? The classical ideal is that everything can be neatly categorized so that for a given class of objects there is a single subcategory for every one of its members. However, the lived world does not conveniently yield to such simplifications. In his Women, Fire and Dangerous Things George Lakoff expounds a modern theory of classification which serves as a good starting point for the analysis of typification both in real life and in fiction. As regards assessment of other people in general on the conscious level we might all too easily succumb to a tendency toward classical categorization in which those assumed to belong to a certain class of people uniformly have certain traits. Open categories with blurred 
boundaries are cognitively much more challenging, but they prompt mental operations which expand rather than limit our understanding of other people and our relationships with them. It also accounts for more interesting character construction both on the side of filmmakers and spectators.

The following is a list of just those features of modern categorization that are relevant in view of the scope of this article. They have also been slightly modified for the present purposes:

- Family resemblances. "[M]embers of a category may be related to one another without all members having any properties in common that define that category."

- Centrality: “[S]ome members are more representative examples of belonging to a category than others."

- Membership gradience: “[A]t least some categories have degrees of membership and no clear boundaries."

- Centrality gradience: “[M] embers (or subcategories) which have degrees of membership and no clear boundaries."

- Basic level categorization: "Categories are not merely organized in a hierarchy from the most general to the most specific, but are also organized so that categories that are cognitively basic are 'in the middle' of a general-to-specific hierarchy. Generalization proceeds 'upward' from the basic level and specialization proceeds 'downward.","

Basic level categorization is likely to be the starting point from which actors in most aesthetic contexts will intuitively adopt in creating characters which are recognizable as socially relevant yet not merely stereotypes. The actor may then move either toward generalization or specification, or even in both directions at the same time, as we shall see. The way generalization operates is likely to have wide ranging ideological implications that may be either circulated and strengthened or questioned and deconstructed in fiction. Genre films are notorious for the former as simplistic 
categorization tempts jumping into conclusions on the basis of prevailing category prejudice.

Typically, this takes place through proclaiming prototypicality to a character having a certain salient trait - positive or negative. Such value judgements may be further strengthened through attaching qualities to an already categorized character in order to reinforce or create easily graspable and affective associations. This is an instance of category being defined according to the supposedly most representative member, perceived as a prototype. It connects with the notion of social stereotypes understood as preconceptions which guide cultural expectations about members of such category. ${ }^{9}$

It is easy to exploit such notions in establishing the fictional truth of a story and the moral stand it implies - possibly with extra-fictional claims. On the at least potentially more noble side easy typification also makes it possible to have types stand for some social or more abstract category in order to, say, make a point about historical development. In many contexts this suffices, but more interesting characterizations emerge when filmmakers venture even further. One of the most fundamental notion of the modern theory of classification is that belonging or not belonging to a category may not be such a clearly-cut thing. Boundaries may be expandable and categories are alive in that they tend to include ever new members and with that become more and more internally diversified. It should also be noted that an individual may belong to several categories of context bound social relevance which may or may not be interdependent. One definition of good acting skill could well be the ability to negotiate social stereotypes in terms of modern classification, displaying a wealth of relationships between different classifications and thus showing the supposedly familiar in new light.

Modern classification may also undermine stereotypes when the classified character is shown not possessing a characteristic thought to be shared by all members of that category or possessing it only to some degree, or by having him or her belong to a certain category only to some degree. The character may also exemplify the arbitrariness of classification, particularly as regards moral 
qualities as well as the heterogeneity of categorization and thus function as an exemplar of the blurredness of category boundaries. Modern categorization thus offers an actor scope for developing characters that can be recognized as, say, exemplifying belonging to a certain class in non-trivial, non-stereotypical ways - allowing for recognition with a difference! Much depends, of course, on the spectator's propensity to rely on either classical or modern principles of classification, as well as on the mode and aims of the mimetic representation. As we shall see, film history offers a great variety of strategies for finding a balance between individualizing and typifying tendencies for various expressive purposes.

\section{Stereotypes and social types}

In what ways and for what purposes does a character exemplify certain general properties? Fictional characters, irrespective of the degree of typification, can be seen as instances of modelling social roles on the basis of embodiment. Paul Ricoeur has suggested that mimesis on the whole should not be understood as imitation, as this word, particularly in connection with Aristotle's Poetics, has usually been translated. Mimesis is an act of composition and construction and thus it does not consist simply of duplicating reality. Rather, it is an instance of metaphoric redescription of a less known domain - human reality - in the light of relationships within a fictitious but better known domain - the tragic tale. ${ }^{10}$ Mimesis is thus modelling in a similar sense as the making of a scientific model with the aim of capturing the relevant features of the object of description in a medium that makes these features more easily perceptible and manageable. The idea of mimesis as modelling applies particularly well to all the types of typification in fiction and transcends customary notions of realism in fiction.

According to some traditional literary scholarship "insofar as a character is a type, he is less a 
character." 11 According to Scholes and Kellogg types emerge from generalization and may take forms such as religious, psychological, physiological, intellectual types, social or geographical types. They see this kind of generalization which emphasize "common, unifying elements in disparate things" 12 as tending towards dehumanization of character. This view is based on seeing the notions of character and type as diametrically opposed: when considering characters as type of one kind or the other, "we are thinking of them not as characters in themselves but as elements which contribute to the whole, as parts of the plot or meaning of a work." 13 There are plenty of instances both in literature and film which are governed by this dichotomy. As James Goodwin summarizes Sergei Eisenstein's notion of typage: “The purpose of typage is to present a perspective on character, not an individualized psychology of character: 'it is important to us to create first and foremost and impression ... of an observer, not the objective coordinates of sign and essence actually composing character." ${ }^{14}$ A crucial difference emerges between typification of the working class, which entails waking into genuine class consciousness and realizing one's role in the political struggle, and negative stereotypes used to point out and disparage the class enemy:

In Eisenstein's imagery, class difference is a difference between visualization through stereotype of the bourgeoisie and through typicality of the proletariat. His treatment makes the ruling class into individualized caricatures, while by comparison the working class, seen in the hundreds in each film, seems an anonymous mass.... In regards to both physiognomy and camera point of view, the working class is an ideal type, distinctive for its physical power, alertness, and collective identity. From this ideal all other social groups - owners, managers, military, priests, the lumpenproletariat - deviate. ${ }^{15}$

Indeed, part of Eisenstein's way of modelling revolution derives from the ideological need to portray the masses as the only genuine revolutionary force. Individualism is inimical to that and so 
the class enemy is portrayed in the form of caricatures that crystallize some aspect thought to be characteristic of the reactionary forces - the greedy capitalist, the pleasure seeking member of the bourgeoisie, the obscurantists priest, the officer all too ready to open fire on the proletariat.

This applies also to the kind of situations depicted. When Eisenstein stages a strike, he does not specify the exact time and place; he describes a historical process on a more general level than individual historical events. The story is essentially about collective action and has to be exemplary rather than historically specific; the spectator is to recognize a more general pattern in class relationships than just a single historical instance. Even more generally, in the Soviet scheme of things, characters are supra-individual exemplifications of social forces. Labels appear by no means arbitrary, on the contrary, they reveal the essence of social relationships. As David Bordwell points out, in these films "characters find their roles within specific generic motivations." These may be 'studies of revolution', dealing with contemporary problems in the newly founded Soviet Union, building an industry or collectivizing the countryside. Such genres offered stories in which characters appear "emblematic of forces within a politically defined situation."16

One could hardly think of a more stubborn insistence of classical categorization, all the more apparent for those of us who do not at least unequivocally share the Marxist ideology of the dialectics of history on which it is based. Everything is organized so as to ensure instant recognition of types and their moral standing. Understandably, Eisenstein did not feel a need to use professional actors in his films depicting revolution: it was enough to find people with a suitable appearance for them to function in an appropriate fashion as parts of the filmic whole. Following the ideas of his mentor Vsevolod Meyerhold he believed in the "primacy of physiological gesture over psychological emotion." "17 As opposed to Stanislavsky's ideal of the actor creating a character from within, the point about Meyerhold's biomechanism was to let the character emerge from the appropriate gesture. For Eisenstein this meant a gesture which in the filmic context would reveal the essence of a member of a social class that was what the audience was supposed to recognize. 
Certain features are heavily emphasized at the expense of any other features a character might be expected to have in order to analyze, criticize or mock a group or type and above all to bring forth in a satirical fashion their social roles. No psychological aspects emerge as in this scheme of things depicting individual traits would be a distraction.

The notion of types in cinema being something opposed to individualized characters and being more or less caricature-like does not belong exclusively to Marxist aesthetics. For Richard Dyer " $[t]$ he type is any character constructed through the use of a few immediately recognizable and defining traits, which do not change or 'develop' through the course of the narrative and which point to general, recurrent features of the human world," whereas "[t]he opposite of the type is the novelistic character, defined by a multiplicity of traits that are only gradually revealed to us through the course of the narrative, a narrative which is hinged on the growth or development of the character and is thus centered upon the latter in her or his unique individuality, rather than pointing outwards to a world." 18 Dyer further claims that

In our society, it is the novelistic character that is privileged over the type, for the obvious reason that our society privileges - at any rate, at the level of social rhetoric - the individual over the collective or the mass. For this reason, the majority of fictions that address themselves to general social issues tend nevertheless to end up telling the story of a particular individual, hence returning social issues to purely personal and psychological ones. ${ }^{19}$

Dyer's notion of types is somewhat analogous to the use of types in Soviet historical-materialist narration and to some extent seems applicable to standard typification in genre films. The main difference is ideological. In the Soviet films the system of typage serves a certain social theory and the intention is to extoll or ridicule certain classes. By contrast, stock characters in mainstream Western cinema may be used to elicit the kind of response in the spectator appropriate for the genre. 
Stock characters may derive from prevailing attitudes toward various groups but their main function is to insure the fluency of the narrative and concentration on standard thematic elements, thus eliciting certain genre related responses. This takes place in a framework tuned to typification throughout, including typical situations analogous to those of Berger and Luckmann's description. Understanding plots and characters in mainstream films is easy because so much is already there before the film begins. Nevertheless, a good actor still has plenty of scope to create a character who we watching the film within the genre context are prepared to appreciate as an individual of sorts. And again, typifying and individuating tendencies can merge: John Wayne became the icon of Westerns because he crystallized an American ideal in his own unique way - film after film.

Nevertheless, the results may be ethically doubtful when they entail a trivialization of moral issues or stereotyping and value laden labelling of cultural, ethnic, sexual, and various other groups. This happens when the characters are conceived in terms of classical categorization, first by the filmmakers, and as cued by the film, by the spectators. This need not be so, as even in mainstream cinema categories of people can be treated as expandable and having blurred boundaries. The point may be even made emphatic by depicting characters who are not aware of such facts of life as narrow minded or misguided. This happens in many films which challenge racial stereotypes.

As a rule more innocently, in popular comedy stock characters serve to elicit laughter as silly traits associated with certain basic social types generate funny situations. In the 1930s the Marx brothers employed this kind typification in a riotous fashion, while in screwball comedies more gently caricatured characters of all types were commonly found in typical situations emerging from misunderstandings and consequent social embarrassment. More generally, typification in genre films serves first of all the purposes of efficient narration within prevailing conventions; the attached attitudes toward various groups appear mainly symptomatically. And most importantly, as screwball comedies so well exemplify, within the depiction of social types, truly memorable characters can emerge. Cary Grant fleshing out easily recognizable but none the less unique 
characters - even while allowing the spectator to be aware of the subtle craft of his acting - excels in such flamboyant acting, say, as the journalist in His Girl Friday (1940), who constantly and hilariously adapts to ever new and more complex situations.

Telling a story about distinct individuals does not necessarily entail compromising the treatment of social issues at great depth. But before discussing examples of that, we should focus on how Dyer has analyzed the way stereotypes can function as a way of conveying beliefs about groups of people. Although constructed iconographically similarly to the way stereotypes are constructed (i.e. only a few verbal and visual traits are used to signal the character), social types can be used in a much more open and flexible way than can stereotypes. This can be most clearly seen in relation to plot. Social types can figure in almost any kind of plot and can have a wide range of roles in that plot (e.g. as hero, as villain, as helper, as light relief, etc.), whereas stereotypes always carry within their very representation an implicit narrative. Following the terms introduced above, stereotypes tend to be tied to prevailing preconceptions in terms of classical categorization, whereas social types are best conceived in terms of the principles of modern classification such as gradience and blurredness of boundaries. From the actor's point of view, the former offers a standard set of conventional models which also guide audience expectations, whereas the latter is open to putting conventions of acting and real life experience into a dynamic relationship with one another and exploring the possibilities of creating highly individuated characters still recognizable as social types within a given context - largely be creating an impression of a certain habitus.

\section{Interactive typification and individuation}

There is no reason why the polarization between characterizing an individual and depicting belonging to some class or another would have to be as extreme as Scholes and Kellogg or Dyer 
suggest. The former do admit that a character "can be considered in terms of his individual characteristics or as a part of some larger scheme" ${ }^{20} \ldots$ "no matter how thoroughly individualized a character may be, for the literate reader he will be the richer through the various modes of family resemblance which connect him to the world of ideas, the social world, and the literary past." ${ }^{21}$ This is in accord with the initial notion of this chapter about how even the appreciation of individuality emerges from the perception of the various discernable traits which connect with our knowledge about what kind of determinants shape people as they are borne into and live in a certain social environment. What was added to this was the way aesthetic conventions shape our perception through our ability to apply principles of classification in a flexible way. However, just like in our real world experience, the way perception of individuality necessarily ties with typification runs much deeper than this.

In exploring how a film models human affairs, it is good to keep in mind Bordwell and Thompson's warning about trying to assess characters merely in terms of realism. What really matters is how a certain style of acting functions in the total context of filmic means employed. Thus, the criterion of an actor's success is whether he or she "looks and behaves in a manner appropriate to his or her character's function in the context of the film ... [rather than] whether or not she looks or behaves as a real person would."22 In Bresson's minimalist Pickpocket (1959) the main character Michel (Martin Lassalle) looks very much the same throughout the film, displaying hardly any facial expressions. ${ }^{23}$ He merely glances somewhat furtively around him, or downwards. His voice-over narration gives some matter of fact information about his inner states, but basically this is not what is at issue. Aesthetically the gist of the film emerges from its overall formalism in which Lassalle's reticent acting perfectly participates. As Bresson seeks to treat spiritual issues rather than realistically depict a fully rounded character he furnishes his protagonist only with minimal social context and psychological traits. Michel is obsessed with pickpocketing and this goes together with his alienation from other people, including all those with whom he could 
conceivably have an affectionate relationship.

However, as Bordwell and Thompson advise us, rather than seeking to understand Michel's behavior in terms of psychological realism we should focus in formalist terms on him as a collection of character traits with certain plot functions. Thompson writes: "Since characters are not people, we do not necessarily judge them by the standards of everyday behavior and psychology. Rather, as with all [filmic] devices and collections of devices, characters must be analyzed in terms of their functions in the work as a whole." ${ }^{24}$ While such extreme formalism in the last instance might be too rigid, it may serve well as the starting point of analysis of a film such as Pickpocket. This film may well be studied as a parable in which each character has a certain plot function serving the overall purpose of exemplifying the point announced in the opening text about a young man being pushed by his weakness into pickpocketing and this leading to two souls being united through strange paths. Thus, while Bresson's character in this as well as in most of his films are much more rounded than those of Eisensteinian typage, they are nevertheless individualized only to the extent of making this parable appear to concern genuinely human issues.

Bresson famously preferred to talk about 'models' rather than 'actors'. As András Kovács aptly summarizes: "A model on the screen is not alive person in any sense, she is pure essence, an abstract person, a spiritual ego detached from all rational connections." ${ }^{25}$ Bresson was striving to present what he conceived as more or less an antithesis to acting, which he disparagingly thought of as an actor pretending to be someone else than he or she is, someone driven by some psychological motivation or other. The model, on the other hand, was supposed to "act like a psychic automaton without any attempt to express inner motivations." ${ }^{, 26}$ What emerges is neither the impression of an individual or a type quite in the sense discussed so far. However, the fairly abstract development that Bresson depicts in his film can only be understood in terms of standard classifications familiar both from our acquaintance with the real world as well as fiction. We need what Bordwell calls prototype schemata which a film evokes, allowing us to identify "individual agents, actions, goals, 
and locales." We also need template schemata, or filing systems, to make sense of the highly elliptical narration Bresson caters to us, allowing for adding absent information and testing of data classification. ${ }^{27}$ But here again we must be aware of too obvious classifications. Right from the opening text Bresson tells us that although we are following the story of someone we recognize as a pickpocket, there is something in him that resists this classification. In the last instance the focus of interest is not Michel's career as a pickpocket, but his spiritual condition with its surprising twist at the very end of the film. The alienating formalism of the narration and the accordingly minimalist, anti-psychological style of presenting the characters (to avoid using the word 'acting'), serve the purpose of redescription of conventional schemata, very much in the manner of modernist classification strategies.

Prototype schemata and templates are needed also in connection with less modernist narration. Individuation may well entail a degree of discrepancy between expectations generally attached to the social type in question, but at least the target audiences of art house films are likely to possess sufficiently flexible cognitive schemata to enjoy the relative openness of categorization. Thus, typification can be employed in a perfectly legitimate fashion in order to address ethical dilemmas on a more general level. Even quite sophisticatedly depicted characters might be made to function as types in order to make more emphatic the point that they stand for certain historical groups. In Bertolucci's 1900 (1976) the three principal male characters clearly stand prototypically for the old aristocracy, fascism and socialism with each character being characterized according to how these classes are morally implicated. In Lakoff's terms this is an instance of metonymic reasoning or presentation. Yet, Robert De Niro and Gérard Depardieu have roles which, while exemplifying complex social relationships, allow them to round their characters beyond the plot functions that make this ideological point. Donald Sutherland, instead, as the fascist Attila is merely a caricature of a brutal fascist.

As we have seen, modelling can take place on a continuum from characters as types as fully 
rounded as a given form of fiction allows, to more or less caricatured treatment of employing characters as exemplifications of social types. To make this point more clear, Dyer's notion of social types should be extended towards György Lukács’ notion of types. Lukács defined type in literature as a crystallization of what is representative in a given social and historical situation. He emphasized that a type is not an average but a concrete and idiosyncratic figuration. Type is not to be thought of as the average or middle distance, a sort of fixed point midway between generality and individuality. Instead, his notion of type ties essentially with Lukács' ideal of realism: "what makes it a type is that all the humanly and socially essential determinations are present on their highest level of development, in the ultimate unfolding of the possibilities latent in them, in extreme presentation of their extremes, rendering concrete the peaks and limits of men and epochs."28 Lukács' view is dialectical through and through: "The point in question is the organic, indissoluble connection between man as a private individual and man as a social being, as a member of a community. ${ }^{29}$ Typification, as he conceives it, is thus inherently mobile, involving a varying intensity of both generalization and individuation. Thus, though in a sense the characters and events of certain nineteenth century novels Lukács analyses are exemplary, these literary figures incarnate social processes through their individuality. Thus, they serve as vehicles for putting forward an element in a wide social panorama. However, there is good reason to expand the scope of typification to cover a broader range of narrative strategies. This by no means detaches the function of typification from serving as a social commentary. While Lukács may be seen as representing a more subtle form of Marxist aesthetics than Eisenstein at least as regards the use of types in fiction, it must be appreciated that the idea is familiar also among scholars hailing from quite different scholarly orientations.

There have been film directors who have sought to achieve just the kind of realism Lukács advocates. Luchino Visconti's The Leopard (1964) serves as a prime example of cinematic rendering of characters as exemplifications of different social classes in a dynamic historical 
situation. The film is an adaptation of a novel of the same name by Giuseppe Tomaso di Lampedusa. Perhaps because the director, like the author, had a very strong family connection with the historical period in question, the Italian Risorgimento amounting to the unification of Italy, he had a clear idea as to how the characters should appear. The protagonist, the Prince of Salina (Burt Lancaster) is a refined portrayal of an aristocrat, who is very much aware of the inevitability of certain historical processes even while adhering to his old fashioned tastes and values. Creating these characters has been largely a question of being able to come up with a plausible habitus that seemingly effortlessly express belonging to a social class in a certain historical situation. The characters have a high degree of centrality as members of their class but without appearing prototypical in the way the three protagonists of 1900 . The plot development nicely makes the point about the nature of the historical change. The prince's counterpart is the upstart Don Calogero (Paolo Stoppa), a businessman whose newly acquired wealth is needed to keep the aristocrats in comfort in the new Italy. The main event of the film which crystallizes the ongoing social process is the meeting of the Prince's nephew Tancredi (Alain Delon) and Don Calogero's daughter Angelica (Claudia Cardinale). Apart from the slight caricaturization of Don Calogero - a touch of satire that neither the author nor director were able to resist - the central characters, in good Lukácsian fashion, are well fleshed out, each of them "unfolding of the possibilities latent in them," thus rendering a subtle image of the historical process depicted. This is manifested particular in the contrast between the Prince and Tancredi. The Prince stands for the old establishment, aware both of the inevitability of the political change (the rise of the economically enterprising middle class) and the inertia that will insure the continuation of the elevated lifestyle of the aristocracy as well as the poverty and squalor of the lower classes. Tancredi, on the other hand, seizes the opportunity, switches sides without compunction and ensures his future prospects through marrying a bourgeois heiress. The Prince's meditations and the narrator's comments as they appear in the novel are discretely infiltrated into the dialogue. However, as Nowell-Smith has aptly pointed out: 
The meaning is conveyed, not just by the words but by a permanent relationship between the man and his surroundings. These is no visual or rhetorical expressionism. Everything is real, but seen in a particular way, reflected through the consciousness of the Prince.

Thus Visconti succeeds in giving filmic expression to Lukács ideal of typification as fully realistic way of expounding ideas about the nature of social relationships.

\section{Conclusion: range of typification}

That typification and individuation need not be thought of as opposite tendencies is in a sense obvious: we generalize on the basis of our experience of individual phenomena and perceive individuality in terms relevant general notions. The notion of habitus neatly captures this dialectic of how individuality can only emerge from conditions of conditions of social existence which in turn are manifested in the variety of individuals they produce. Sensitivity to how these things work out allows for a talented actor to create highly individualized characters who may all the more persuasively be recognized as being representative and socially or existentially relevant. We as spectators are remarkably capable of recognizing human traits and types even when they are barely suggested: when not actually blocked against doing so, we will almost involuntarily fill in features which will round a social type or even a stereotype into a believable character. At its most obvious this filling in may take place in terms of classical, effectively heavily ideologically bound classification allowing for both easy recognition and misrecognition: either falling into the trap of accepting reductive stereotypification or simply missing the heterogeneity that would be available in the representation. In the best of cases even recognition of sameness in otherness may take place, 
that is, flexibility of categorization allows for refiguring of understanding of social types in terms proposed by the narrative mimesis, perhaps to the extent of enriching the spectators view of him- or herself.

\section{References}

${ }^{1}$ Robert Scholes and Robert Kellogg, The Nature of Narrative (London, Oxford and New York: Oxford University Press, 1987), 87.

${ }^{2}$ In literary theory characters are usually discussed in terms of flat and round. As E.M. Forster discusses these, flat characters "are sometimes called types and sometimes caricatures." Forster. E.M. Aspects of the Novel. Harmondsworth: Penguin Books, 1963), 75.

${ }^{3}$ Erving Goffman, The Presentation of Self in Everyday Life (Harmondsworth: Penguin Books, 1987), 13.

${ }^{4}$ Peter Berger and Thomas Luckmann, The Social Construction of Reality: A Treatise in the Sociology of Knowledge (Harmondsworth: Penguin Books, 1987), 45.

5 ibid., 46.

${ }^{6}$ Pierre Bourdieu, The Logic of Practice, trans. Richard Nice (Stanford: Stanford University Press, 1990), 56-57. Bourdieu has written about the notion of habitus in several of his works.

7 For a thorough analysis of body language as the measure of fictional truth in this film see http://www.kosmorama.org/ServiceMenu/05-English/Articles/Expressing-suppression.aspx

${ }^{8}$ George Lakoff, Women, Fire, and Dangerous Things - What Categories Reveal about the Mind (Chicago and London: The University of Chicago Press, 1987), 12-13.

9 ibid., 85. 
${ }^{10}$ Paul Ricoeur, The Rule of Metaphor: Multi-disciplinary studies of the creation of meaning in language, trans. Robert Czerny with Kathleen McLaughlin and John Costello, sj. (London and Henley: University of Toronto Press, 1978), 244.

11 Robert Scholes and Robert Kellogg, The Nature of Narrative (London, Oxford and New York: Oxford University Press, 1987), 204.

12 ibid.

13 ibid.

14 James Goodwin, Eisenstein, Cinema, and History (Urbana: University of Illinois Press, 1993), 71. Quotation from Sergei Eisenstein, Film Form (New York and London: A Harvest/ HBJ Book, 1977), 127.

15 ibid., 72-73.

16 David Bordwell, Narration in the Fiction Film (London: Routledge, 1988), 236.

17 Peter Wollen, Signs and Meaning in the Cinema (London: Secker and Warburg in association with the British Film Institute, 1972), 28.

${ }^{18}$ Richard Dyer, "The Role of Stereotypes", in Paul Marris and Sue Thornham, Media Studies - A Reader (Edinburgh: Edinburgh University Press, 3rd edition, 2009), 208

19 ibid., 209.

${ }^{20}$ Robert Scholes and Robert Kellogg, The Nature of Narrative (London, Oxford and New York: Oxford University Press, 1987), 205.

21 ibid., 206.

${ }^{22}$ David Bordwell and Kristin Thompson, Film Art: an introduction, International edition (New York: McGraw-Hill, 1993), 160-161. 
23 The scene in which Michel arrives to his mother's deathbed constitutes a minor exception: for a passing moment his face looks just slightly contorted. This is needed to indicate that he is not entirely callous. Also, during his last encounter with the police inspector, he does momentarily loose his nerve.

${ }^{24}$ Kristin Thompson, Breaking the Glass Armor - Neoformalist Film Analysis (Princeton: Princeton University Press, 1988), 40.

${ }^{25}$ András Bálint Kovács, Screening Modernism - European Art Cinema, 1950-1980 (Chicago and London: The University of Chicago Press, 2007), 147.

${ }^{26}$ ibid.

${ }^{27}$ David Bordwell, Narration in the Fiction Film (London: Routledge, 1988), 34.

28 Georg Lukács, Georg. Studies in European Realism: A Sociological survey of the Writings of Balzac, Stendhal, Zola, Tolstoy, Gorki and Others (London: The Merlin Press, 1972), 6. ${ }^{29}$ ibid., 8. 